\title{
SOCIAL INSTITUTIONS TRANSFORMATION AS A FACTOR OF THE SOCIALAND ECONOMIC DEVELOPMENT OF MODERN RUSSIA
}

\author{
Elena V. Loginova \\ Volzhsky branch of Volgograd State University, Volzhsky, Russian Federation \\ Natalia V. Loseva \\ Volzhsky branch of Volgograd State University, Volzhsky, Russian Federation
}

Aleksandr A. Polkovnikov

Volzhsky branch of Volgograd State University, Volzhsky, Russian Federation

\begin{abstract}
The systemic determinacy of modern Russian society in time and space coordinates allows us to conclude that it is at the process stage of the life cycle of the large-scale social and economic systems functioning within the stage of the digital age that is characterized by the features of environmental systems. It means that the logic of the social and economic development of modern Russia is to ensure the harmonization of the performance and state of all economic systems through communication and coordination, as well as creating conditions for transactions. Following this logic, the article proves the possibility of considering it as a factor providing conditions for socio-economic development using the example of the transformation of the public administration institution. The article defines the subject-object and structural content of the public administration institution. By using the matrix approach, the authors characterize the evolutionary dynamics of the public administration institution. It makes it possible to draw a conclusion about the formation within the local civilizational matrix of modern Russia of a new type of the institutional core - the intellectual one, in which basic and compensatory institutions of the market and distribution types are integrated. The article presents a methodology that allows determining the degree of the formation of public administration, as well as assessing its impact on the social and economic development of modern Russia.
\end{abstract}

Key words: digital technologies, public administration institution, evolutionary dynamics, institutional matrix, transformation, factor of socio-economic development.

Citation. Loginova E.V., Loseva N.V., Polkovnikov A.A. Social Institutions Transformation as a Factor of the Social and Economic Development of Modern Russia. Journal of Volgograd State University. Economics, 2020, vol. 22, no. 2, pp. 50-61. (in Russian). DOI: https://doi.org/10.15688/ek.jvolsu.2020.2.5

\section{ТРАНСФОРМАЦИЯ СОЦИАЛЬНЫХ ИНСТИТУТОВ КАК ФАКТОР СОЦИАЛЬНО-ЭКОНОМИЧЕСКОГО РАЗВИТИЯ СОВРЕМЕННОЙ РОССИИ}

\section{Елена Викторовна Логинова}

Волжский филиал Волгоградского государственного университета, г. Волжский, Российская Федерация

\section{Наталия Владимировна Лосева}

Волжский филиал Волгоградского государственного университета, г. Волжский, Российская Федерация 


\section{Александр Александрович Полковников}

Волжский филиал Волгоградского государственного университета, г. Волжский, Российская Федерация

Аннотация. Системная определенность современного российского общества в координатах времени и пространства позволяет сделать вывод о его нахождении на процессной стадии жизненного цикла функционирования масштабных социально-экономических систем в рамках этапа цифрового века, которому присущи черты средовых систем. Это означает, что логика социально-экономического развития современной России заключается в обеспечении гармонизации деятельности и состояния всех экономических систем посредством коммуникации и координации, а также создания условий для трансакций. Следуя этой логике, в статье на примере трансформации института публичного управления доказывается возможность рассмотрения ее в качестве фактора, обеспечивающего условия для социально-экономического развития. В статье определено субъектно-объектное и структурное содержание института публичного управления. На основе использования матричного подхода охарактеризована эволюционная динамика института публичного управления, что позволило сделать вывод о формировании в рамках локальной цивилизационной матрицы современной России нового типа институционального ядра - интеллектуального, в котором происходит интеграция базовых и компенсаторных институций рыночного и раздаточного типа. Авторами представлена методика, позволяющая определить степень сформированности публичного управления, а также оценить его влияние на социально-экономическое развитие современной России.

Ключевые слова: цифровые технологии, институт публичного управления, эволюционная динамика, институциональная матрица, трансформация, фактор социально-экономического развития.

Цитирование. Логинова Е. В., Лосева Н. В., Полковников А. А. Трансформация социальных институтов как фактор социально-экономического развития современной России // Вестник Волгоградского государственного университета. Экономика. - 2020. - Т. 22, № 2. - С. 50-61. - DOI: https://doi.org/10.15688/ ek.jvolsu.2020.2.5

\section{Введение}

Проблемы анализа факторов социальноэкономической динамики и их влияния на эволюцию экономических структур и институтов всегда выступали в качестве определяющих предметное поле для исследований в рамках экономической науки, особенно в те периоды, когда общество переживало переход от одного качественного состояния в другое. Подобное - переходное - состояние характерно и для современного общества, поскольку под влиянием технологических трансформаций доминирующим условием социального прогресса становится развитие человека и присущих ему способностей, все большая доля социально-экономических трансакций осуществляется посредством цифровых информационно-коммуникационных технологий, что приводит к изменениям в функциях факторов общественного производства [Логинова, 2019, c. 17-18], а также способствует трансформации существующих социальных институтов и возникновению новых.

По мнению Г. Клейнера, развитие цифровых технологий способствует формированию особой стадии развития экономики - ин- теллектуальной экономики, где в качестве основного ресурса и результата деятельности экономических агентов и систем выступает интеллект, который проявляется в системной постановке и решении задач, основанных на построении системы координат, определении положения каждого явления в исследуемой предметной сфере и соответственно движения в данной сфере. Основными субъектами и структурными элементами интеллектуальной экономики являются «экономические системы, наделенные системным интеллектом, обеспечивающим возможность взаимодействия и развития разнообразных социально-экономических систем». Именно «интеллигентность» системы определяет ее способность к взаимодействию с другими системами «с целью обеспечения пролонгирования функционирования данной системы во времени и в пространстве», смягчая «неравенство в многоуровневых иерархических системах управления, в том числе в отношениях “принципал - агент"» [Клейнер, 2020].

Исходя из системной определенности современного общества в координатах времени и пространства, оно находится на процессной стадии жизненного цикла функционирования 
масштабных социально-экономических систем в рамках этапа цифрового века, которому присущи черты средовых систем [Клейнер, 2020]. Это означает, что логику социально-экономического развития современной России можно представить как обеспечение гармонизации деятельности и состояния всех экономических систем (миссия процессной системы [Клейнер, 2007]) посредством коммуникации и координации, а также создания условий для трансакций (миссия средовой системы [Клейнер, 2007]). Следуя этой логике, можно предположить, что трансформация институтов (типовой представитель средовых систем), в том числе социальных, способствует распространению инноваций на всю социально-экономическую систему, обеспечивая ее развитие.

Д. Львов отмечал, что адекватное отражение происходящих изменений в результатах научных исследований возможно посредством преодоления разобщенности и профессиональной замкнутости «ученых, развивающих институциональные концепции в рамках узко дисциплинарных “картин социального мира”. Спектр вопросов, требующих глубокого институционального изучения, очень широк, и сами по себе его не в состоянии полностью охватить ни экономическая наука, ни социология, ни государствоведение. Необходимо активизировать совместные разработки в рамках блока общественных наук, в том числе и в исследовании институциональных проблем» [Homo institutius, 2005]. О значимости интеграции наук об обществе говорил и О. Иншаков, подчеркивая, что преодоление разобщенности сформировавшегося конгломерата институциональной теории позволит осуществить переход от односторонности в исследовании институтов общества к системности представлений о них [Иншаков, 2003б].

\section{Результаты и обсуждения}

Прежде чем рассуждать о влиянии трансформации социальных институтов на эволюцию социально-экономической системы, необходимо дать категориальную определенность понятиям «институт», «институция» и «организация», поскольку «нечеткость понятийной системы институционализма, упрощение или, напротив, чрезмерное расши- рение определений его основных категорий порождают искаженное отражение и торможение процессов практической модернизации хозяйственной действительности» [Иншаков, 2007, c. 7].

Системно структурированная характеристика категорий «институт», «институция» и «организация» представлены в работах Волгоградской научной экономической школы, основателем которой являлся О. Иншаков. Согласно выработанному в рамках данной научной школы подходу, «суть институции - в социальной форме персонифицированного закрепления образа действия, порождающего образ мышления ее агентов. Поэтому институцию следует понимать онтологически как отношение между людьми по поводу дифференциации деятельности или как форму социализации деятельной функции человека» [Иншаков, 2010, с. 30]. Организация же представляет собой целевой комплекс комплементарных институций, исполняемых ее агентами в интегрированной системе правил и норм. Свой видовой статус организация определяет посредством институции и масштабно закрепляет его посредством института [Иншаков, 2010, c. 34].

В логике генетической теории факторов производства [Иншаков, 2002, 2003а] соединение комплементарных факторов Ins и $O$ создает институты как видовые комплексы взаимодействия институций и организаций $(W)[$ Иншаков, 2007, с. 9]. Категория «институт» в данной трактовке выводится «не прямо из категории “институции", а опосредованно - через категорию “организации”, то есть “в прямой связи эндогенных факторов любого производства институция (Ins), обретая организацию $(O)$ своего воспроизводства, образует соответствующий себе институт (Ins $\rightarrow O) \rightarrow($ Inst)"» [Иншаков, 2010, с. 34-35]. Продолжая эту логику и объединив комплементарные факторы $A$ (человеческий) и $T$ (технико-технологический) в технологии $(V)$ как видовые комплексы взаимодействия человека и техники, О. Иншаков построил уравнение производственной функции $-Q=F(V, M, W, I n f)$ [Иншаков, 2007], доказывающее влияние институтов, являющихся интрафакторами системы общественного производства, на социально-экономическое развитие. 
Для иллюстрации подобного влияния в качестве примера рассмотрим процесс трансформации института публичного управления и предложим методику оценки последствий этого процесса для социально-экономического развития современной России.

В научный оборот категория «публичное управление» впервые была введена в 1887 г. В. Вильсоном, но свою подлинную сущность она приобрела в конце XX - начале XXI в. под влиянием двух факторов: во-первых, в результате усиления процесса социализации каждому человеку все больше становится присущ статус homo institutius, реализация которого позволяет осуществлять институционально обусловленный выбор модели поведения в системе публичного управления; вовторых, благодаря развитию цифровых технологий, прежде всего Интернет, появилась возможность осуществлять устойчивые взаимодействия между субъектами в режиме реального времени и вне пространственных ограничений.

С точки зрения субъектно-объектной определенности институт публичного управления можно охарактеризовать как отношения, складывающиеся между гражданами, общественными ассоциациями, предпринимательскими сообществами и органами государственной и муниципальной власти по поводу согласования баланса интересов относительно целей социально-экономического развития [Loginova et al., 2018].

В структурной характеристике публичное управление представляет собой институт, который в результате взаимодействия присущих ему функциональной и элементной подструктур на каждом этапе своей эволюции создает и воспроизводит правила поведения в процессе принятия решений по поводу использования экономических ресурсов.

Функциональную подструктуру института публичного управления формирует система институций, содержание которых определяется социальными отношениями по обособлению и закреплению общественно признанных и воспроизводимых типичных действий субъектов публичного управления, являющихся его агентами. Институции по своей сути являются движущей силой в системе публичного управления, поскольку отражают транс- формацию социальных форм функций его агентов, определяющую эволюцию их статусов и ролей в общественном разделении труда. Более того, объекты возникающих в системе публичного управления отношений также принимают на себя институции и статусы, соответствующие их функциям в системе общественного воспроизводства.

Элементная подструктура института публичного управления определяется его организацией, которая конституирует социальные формы взаимодействий агентов публичного управления, тем самым обусловливая складывающиеся между ними отношения. О. Иншаков определял организацию как устойчивую систему отношений между субъектами, выполняющими различные функции в процессе достижения общей цели, которая связывает воедино различные институции и институты, устанавливая их координацию и субординацию и осуществляясь в то же время на их основе [Иншаков, 2003б, с. 44].

Результатом взаимодействия функциональной (институции) и элементной (организации) структур института публичного управления является его эволюционная динамика, которая в конечном итоге порождает «новые образования и эффекты в социально-экономических системах» [Иншаков, 2010, с. 34].

Определить вектор эволюции института публичного управления возможно на основе матричного подхода к теории институциональных трансформаций, разрабатываемого в рамках Новосибирской экономико-социологической школы [Бессонова, 2006, 2008].

Согласно О. Бессоновой, закономерности развития человеческой цивилизации на глобальном уровне, формирующие универсальные этапы ее эволюции, определяются глобальной цивилизационной матрицей, в основе которой заложен институциональный архетип, образующий способы координации коллективных действий вне привязки к конкретным времени и пространству. Институциональный архетип имеет дуальную природу, поскольку состоит из двух типов координации - рынка и раздатка, которые представляют собой универсальные модели взаимодействия, построенные по принципу «доминантности - компенсаторности» одной из сторон архетипа. В рамках локальных социаль- 
но-экономических систем по образу глобальной цивилизационной матрицы выстраиваются локальные цивилизационные матрицы, основным элементом которых является институциональное ядро, определяемое доминантностью одной из сторон институционального архетипа и формирующее институциональную матрицу, имеющую временную и пространственную определенность взаимодействия базовых и компенсаторных институтов. Эволюция локальных цивилизационных матриц осуществляется посредством последовательной смены четырех фаз - перинатальной, структурированной, институционального исчерпания и институциональных трансформаций. На перинатальной фазе происходит процесс оформления базовых институтов в рамках институционального ядра, в структурированной фазе базовые институты приобретают свою устойчивую форму, упорядочивается их взаимодействие с компенсаторными институтами. На фазе институционального исчерпания базовые институты уже не способны обеспечивать эффективное функционирование социально-экономической системы, активизируются компенсаторные институты, причем, как правило, в стихийных нелегитимных формах, что приводит к обострению кризисных явлений в экономике и обществе. В период институциональных трансформаций происходит изменение природы институционального ядра, так как доминирующие функции в нем начинают играть компенсаторные институты, тем самым обеспечивая устаревшим формам базовых институтов возможность для трансформации [Бессонова, 2006, с. 92-93].

В своих исследованиях О. Бессонова выделяет начальный, срединный, зрелый и интегральный этапы развития (формации) локальных цивилизационных матриц, и отмечает, что переход от первой ко второй, и от второй к третьей формации является результатом институциональных трансформаций. Для перехода же на четвертую - интегральную формацию институциональной трансформации недостаточно, необходим цивилизационный прорыв, под которым О. Бессонова понимает смену принципов построения локальной цивилизационной матрицы, обусловленную внедрением информационных технологий в практи- ческую деятельность социальных субъектов [Бессонова, 2006, с. 95].

Логика эволюционного процесса, по О. Бессоновой, заключается в поступательном движении цивилизационной матрицы с одного уровня развития на другой. При этом на каждом последующем уровне решаются проблемы предыдущего, что способствует переходу «на новую ступень материального и духовного совершенствования〉 [Бессонова, 2006, c. 87] и подтверждает тезис о влиянии институциональных изменений (трансформаций) на развитие социально-экономической системы.

Используя совокупный научный потенциал Волгоградской и Новосибирской школ, рассмотрим процесс эволюционной динамики института публичного управления в современной России.

В качестве исходных предпосылок анализа установим следующее:

- анализ целесообразно начать с 1990-х гг., когда в России начался процесс радикальной трансформации, и завершить 2050 г., так как, по мнению многих исследователей, именно в этот период времени ожидается окончание цифрового века вследствие «полной реализации возможностей электронных компьютерных устройств и завершения действия закона Мура» [Клейнер, 2020];

- тип институционального ядра определяет организацию форм взаимодействия субъектов публичного управления;

- поскольку мы будем рассматривать эволюцию не социально-экономической системы в целом, а отдельного ее института, то вместо базовых и компенсаторных «институтов» будем анализировать базовые и компенсаторные «институции»;

- используя распространенную в отечественной институциональной теории терминологию [Кирдина, 2005, 2007, 2013], матрицу, в структуре институционального ядра которой базовыми институциями являются институции рыночного типа, определим как $Y$-матрица, а матрицу с базовыми институциями раздаточного типа $-X$-матрица;

- результатом цивилизационного прорыва, обусловленного развитием цифровых технологий, становится формирование нового типа институционального ядра - интеллектуального, в котором происходит не только про- 
цесс интеграции базовых и компенсаторных институций рыночного и раздаточного типа, но и возникают новые «цифровые» институции. В этой связи матрицу, соответствующую интеллектуальному ядру, обозначим как $D$ (Digital)-матрица;

- для интеллектуальной экономики [Клейнер, 2020] (сетевой экономики [Логинова, 2019]), базирующейся на цифровых технологиях, доминантным является не рыночный и не раздаточной способ координации, а сетевой [Логинова, 2019], что, на наш взгляд, позволяет сделать вывод о смене дуальности институционального архетипа на триаду («все движется и ничто не остается на месте» (Гераклит)).

С учетом перечисленных предпосылок анализа, эволюцию институциональной матрицы публичного управления можно представить в следующем виде (табл. 1).

Количественную оценку эволюционной динамики института публичного управления предлагается осуществлять на основе разработанного авторами информационно-анали- тического комплекса мониторинга публичного управления в регионах России, основой которого стала математическая модель, позволяющая установить регрессионную зависимость между определяющими факторами, конституирующими институт публичного управления, и результирующими факторами, отражающими степень его сформированности [Оценка реализации публичного ... , 2017; Loginova et al., 2018].

В качестве инструмента построения модели и анализа количественных значений определяющих и результирующих факторов был использован язык программирования Python и его библиотеки [Оценка реализации публичного ... , 2017; Loginova et al., 2018]. Однако было определено, что применяемые регрессионные модели анализа (линейная регрессия, Лассо-регрессия и $A R D$-регрессия) не всегда дают удовлетворительные результаты, поскольку линейные регрессионные модели могут использоваться только для моделирования очень простых задач, где, например, имеется явная линейная зависимость признаков

Таблица 1

\section{Эволюция институциональной матрицы публичного управления} в современной России

\begin{tabular}{|c|c|c|c|}
\hline $\begin{array}{c}\text { Фазы } \\
\text { институционального цикла }\end{array}$ & $\begin{array}{c}\text { Тип институцио- } \\
\text { нального ядра }\end{array}$ & Базовые институции & $\begin{array}{c}\text { Компенсаторные } \\
\text { институции }\end{array}$ \\
\hline $\begin{array}{l}\text { Фаза институционального } \\
\text { исчерпания (90-е гг. XX в.) }\end{array}$ & $\begin{array}{c}\text { Раздаточный } \\
\text { (X-матрица) }\end{array}$ & $\begin{array}{l}\text { Подданство } \\
\text { Естественные и этнические формы } \\
\text { объединения } \\
\text { Кооперация } \\
\text { Государственный контроль }\end{array}$ & Выборы \\
\hline $\begin{array}{l}\text { Фаза институциональной } \\
\text { трансформации (2000- } \\
2020 \text { гг.) }\end{array}$ & $\begin{array}{c}\text { Раздаточный } \\
\text { (X-матрица) }\end{array}$ & $\begin{array}{l}\text { Подданство } \\
\text { Естественные и этнические формы } \\
\text { объединения } \\
\text { Кооперация } \\
\text { Государственный контроль }\end{array}$ & $\begin{array}{l}\text { Выборы Конкурен- } \\
\text { ция }\end{array}$ \\
\hline $\begin{array}{l}\text { Перинатальная фаза } \\
\text { (2020-2030 гг.) }\end{array}$ & $\begin{array}{l}\text { Рыночный } \\
\text { ( } Y \text {-матрица) }\end{array}$ & $\begin{array}{l}\text { Подданство } \\
\text { Конвенциальный и легитимный ха- } \\
\text { рактер норм и правил } \\
\text { Конкуренция } \\
\text { Самоуправление и субсидиарность } \\
\text { Краудфандинг }\end{array}$ & $\begin{array}{l}\text { Многопартийность } \\
\text { и демократическое } \\
\text { большинство } \\
\text { Кооперация } \\
\text { Государственный } \\
\text { контроль }\end{array}$ \\
\hline $\begin{array}{l}\text { Структурированная фаза } \\
\text { (2030-2050 гг.) }\end{array}$ & $\begin{array}{c}\text { Интеллектуальный } \\
\text { (D-матрица) }\end{array}$ & $\begin{array}{l}\text { Гражданство } \\
\text { Многопартийность и демократиче- } \\
\text { ское большинство } \\
\text { Гражданственность } \\
\text { Краудсорсинг } \\
\text { Общественный контроль }\end{array}$ & $\begin{array}{l}\text { Самоуправление } \\
\text { субсидиарность } \\
\text { Государственный } \\
\text { контроль }\end{array}$ \\
\hline
\end{tabular}

Примечание. Составлено авторами по: [Бессонова, 2006, 2008; Кирдина, 2005, 2007, 2013; Кирдина-Чэндлер, 2018; Homo institutius, 2005]. 
или же два класса в задаче классификации могут быть разделены прямой линией. Однако большинство задач, которые возникают при анализе сформированности публичного управления, не являются линейно разделимыми и не содержат линейных зависимостей.

Это вызвало необходимость расширить исследовательский инструментарий за счет применения нейронных сетей глубокого обучения [Loginova et al., 2020]. Метод нейронных сетей зарекомендовал себя как эффективный инструмент моделирования, позволяющий на основании автоматической обработки большого количества данных выделять существующие между ними зависимости [Coзыкин, 2017].

Решение задачи прогнозирования значений показателей, характеризующих динамику результирующих факторов в результате изменений в значении показателей определяющих факторов, на основе использования нейронных сетей осуществлялось на примере регионов Южного федерального округа.

В качестве результирующих факторов были определены «количество зарегистрированных организаций территориально-общественного самоуправления», «участие граждан в деятельности социально ориентированных некоммерческих организаций», которые позволяют сделать вывод о степени готовности граждан объединяться для решения вопросов, связанных с реализацией коллективных и/или общественных интересов. Третьим результирующим фактором был выбран показатель, характеризующий долю населения, участвующего во взаимодействиях с органами государственной власти и местного самоуправления.

Подробное описание определяющих факторов представлено в предыдущих исследованиях авторов [Оценка реализации публичного ..., 2017; Loginova et al., 2018].
На основании сбора статистических показателей, характеризующих значение результирующих и определяющих факторов по регионам Южного федерального округа за 20142017 гг., была сформирована база данных, хранящаяся в формате $C S V$. Для обработки отобранных данных была использована нейронная сеть глубокого обучения с двумя промежуточными слоями по 64 нейрона в каждом и с одним одномерным слоем для получения данных. В качестве функции потерь выбрана MSE (Mean Square Error), в качестве функции для наблюдения ошибки предсказания - MAE (Mean Absolute Error) [Шолле, 2018].

Оценка работы модели осуществлялась посредством перекрестной проверки по $K$ блокам.

В целях определения зависимости между результирующими и определяющими факторами был выбран алгоритм управляемого обучения («обучение с учителем»), суть которого заключается в обучении сети на примере известных значений «входных» данных (показатели определяющих факторов) и «выходных» данных (показатели результирующих факторов), зависимость между которыми была установлена эмпирическим путем.

В исследовании были задействованы библиотеки, написанные для языка программирования Python.

Моделирование зависимостей результирующих факторов от значений определяющих факторов на основе использования метода нейронных сетей осуществлялось посредством многократного разбиения данных на обучающие и тренировочные.

Полученная модель была проверена на тестовых данных (табл. 2).

Абсолютная ошибка увеличилась незначительно, что свидетельствует о хорошей коррелируемости между определяющими факторами и результирующим фактором «ко-

Таблица 2

Результаты проверки модели на тестовых данных для фактора «количество зарегистрированных организаций территориально-общественного самоуправления»

\begin{tabular}{|c|c|}
\hline Предсказания & Реальные данные \\
\hline$[3,6608388]$ & 6,02 \\
\hline$[3,7308018]$ & 2,13 \\
\hline
\end{tabular}

Примечание. Составлено авторами. 
личество зарегистрированных организаций территориально-общественного самоуправления», что позволяет сделать вывод об адекватности построенной модели.

Подобные манипуляции были проведены и на остальных результирующих факторах, но уже с обучающими данными (табл. 3).

Результаты, представленные в таблице 3 , позволяют определить, что у модели начался процесс переобучения, поскольку предсказание данных на обучающих наборах точнее, чем на тестовом.

Следующим этапом работы с полученной моделью было определение набора данных, зависимость от которых значений результирующих факторов не наблюдается и, следовательно, от которых не зависят результаты прогноза. В этих целях была использована оценка относительной разницы среднеквадратичных ошибок моделей с включенными в модель переменными и без них. В результате из модели были исключены без риска снижения качества предсказания те переменные, для которых значение относительной разницы среднеквадратичной ошибки больше 0,1 (ошибка без переменной на $10 \%$ и больше лучше, чем оценка с этой переменной).

После исключения незначимых показателей был произведен перерасчет моделей на правильных наборах параметров, результаты которого представлены в таблице 4.
Сравнение результатов, представленных в таблицах 2-4, по соответствующим факторам позволяет сделать вывод о том, что вследствие переобучения нейронной сети произошло улучшение качества прогнозных значений, и поскольку прогнозные значения достаточно близки к реальным данным, метод нейронных сетей глубокого обучения может служить основой для мониторинга института публичного управления и оценки влияния его трансформации на социально-экономическое развитие современной России.

\section{Заключение}

Институты выполняют системообразующую функцию в обществе, которая заключается в упорядочивании взаимодействий акторов посредством формирования комплекса их возможного и предсказуемого поведения, тем самым способствуя развитию «структуры существования социума - и экономики как его подсистемы - в изменяющейся внешней среде и при эндогенных изменениях в обществе... Если нет институтов, то нет и социальных систем, разновидностью которых является экономика» [Кирдина, 2013], что еще раз подтверждает обоснованность рассмотрения трансформации социальных институтов в качестве фактора социально-экономического развития. Следовательно, основной вопрос заключается не в том, «влияют ли трансфор-

Таблиияа 3

Результаты проверки модели на обучающих данных

\begin{tabular}{|l|c|c|}
\hline \multicolumn{1}{|c|}{ Фактор } & Предсказания & Реальные данные \\
\hline Доля населения, взаимодействовавшего с органами государственной & {$[62,050335]$} & 68,1 \\
\cline { 2 - 3 } власти и местного самоуправления & {$[67,504192]$} & 73,6 \\
\hline Участие граждан в деятельности социально ориентированных неком- & {$[0,9690104]$} & 1,01 \\
\cline { 2 - 3 } \begin{tabular}{l} 
мерческих организаций \\
\hline
\end{tabular}
\end{tabular}

Примечание. Составлено авторами.

Таблича 4

Результаты перерасчета моделей на правильных наборах параметров

\begin{tabular}{|l|c|c|}
\hline \multicolumn{1}{|c|}{ Фактор Реальные данные } \\
\hline $\begin{array}{l}\text { Количество зарегистрированных организаций территориально- } \\
\text { общественного самоуправления }\end{array}$ & {$[4,9751985]$} & 6,02 \\
\hline Доля населения, взаимодействовавшего с органами государственной & {$[1,9583646]$} & 2,13 \\
\cline { 2 - 3 } $\left.\begin{array}{l}\text { власти и местного самоуправления } \\
\text { Участие граждан в деятельности социально-ориентированных неком- } \\
\text { мерческих организаций }\end{array}\right][0,050335]$ & 68,1 \\
\cline { 2 - 3 } & {$[0,9890104]$} & 73,6 \\
\hline
\end{tabular}

Примечание. Составлено авторами. 
мации или не влияют», а в том, как степень этого влияния измерить и оценить его последствия. В результате проведенного исследования авторы пришли к выводу о том, что применение методов математической статистики и машинного обучения позволяет осуществить отбор значимых показателей, динамика количественных значений которых отражает качественные характеристики трансформации социальных институтов. В этой связи для прогнозирования зависимости социально-экономического развития России от динамики и вектора институциональных изменений предлагается использовать метод нейронных сетей глубокого обучения, который зарекомендовал себя как эффективный инструмент моделирования, позволяющий на основании автоматической обработки большого количества данных выделять существующие между ними зависимости.

\section{СПИСОК ЛИТЕРАТУРЫ}

Бессонова, О. Э. Раздаточная экономика России: эволюция через трансформации / О. Э. Бессонова. - М. : РПЭН, 2006. - 143 с.

Бессонова, О. Э. Вектор институционального развития России: от квазирынка к либеральному раздатку / О. Э. Бессонова // Экономическая социология. - 2008. - Т. 9, № 2. - С. 15-28.

Иншаков, О. В. Теория факторов производства в контексте экономики развития : науч. докл. на общем собрании МАОН (г. Москва, 29 ноября 2002 г.) / О. В. Иншаков. - Волгоград : Изд-во ВолГУ, 2002. - 92 с.

Иншаков, О. В. «Ядро развития» в контексте новой теории факторов производства / О. В. Иншаков // Экономическая наука современной России. - 2003а. - № 1. - С. 11-25.

Иншаков, О. В. Экономические институты и институции: к вопросу о типологии и классификации / О. В. Иншаков // Социологические исследования. - 2003б. - № 9. - С. 42-51.

Иншаков, О. В. Институты и институции в современной экономической теории / О.В.Иншаков // Вестник Волгоградского государственного университета. Серия 3, Экономика. Экология. -2007 . - № 11. - С. 6-21.

Иншаков, О. В. Институция и институт: проблемы категориальной дифференциации и интеграции / О. В. Иншаков // Экономическая наука современной России. - 2010. - № 3 (50). C. $26-38$.
Кирдина, С. Г. Об институциональных матрицах: тезисы теории / С. Г. Кирдина. - 2005. - Электрон. текстовые дан. - Режим доступа: http:// www.kirdina.ru/index.php?option $=\mathrm{com}_{-}$ content\&view=article\&id=238 (дата обращения: 10.06.2020). - Загл. с экрана.

Кирдина, С. Г. Модели экономики в теории институциональных матриц / С. Г. Кирдина // Экономическая наука современной России. 2007. - № 2 (37). - С. 34-51.

Кирдина, С. Г. Методологический индивидуализм и методологический институционализм / С. Г. Кирдина // Вопросы экономики. -2013. № 10. - C. 66-89. - DOI: 10.32609/0042-87362013-10-66-89.

Кирдина-Чэндлер, С. Г. Западные и не-западные институциональные модели во времени и пространстве / С. Г. Кирдина-Чэндлер // Вопросы теоретической экономики. - 2018. - № 1. C. 73-88.-DOI: 10.24411/2587-7666-2018-00005.

Клейнер, Г. Б. Системная парадигма в экономических исследованиях: новый подход / Г. Б. Клейнер // Цивилизация знаний: российские реалии : тр. Восьмой науч. конф., г. Москва, 2021 апреля 2007 г.- М. : РосНОУ, 2007. - С. 1-10. Электрон. текстовые дан. - Режим доступа: https://kleiner.ru/wp-content/uploads/2014/12/ Sistemnaya-paradigma-v-e\%60konomicheskihissledovaniyah.pdf. - Загл. с экрана.

Клейнер, Г. Б. Интеллектуальная экономика цифрового века. Цифровой век: шаги эволюции / / Экономика и математические методы. 2020. - T. 56, № 1. - C. 18-33. - DOI: 10.31857/ S042473880008562-7. - Электрон. текстовые дан. - Режим доступа: https://emm.jes.su/ S042473880008562-7-1 (дата обращения: 19.06.2020). - Загл. с экрана.

Логинова, Е. В. Цифровые координаты современного российского общества: методология исследования / Е. В. Логинова // Вестник Волгоградского государственного университета. Экономика. - 2019. - Т. 21, № 3. - С. 15-28. DOI: https://doi.org/10.15688/ek.jvolsu.2019.3.2.

Оценка реализации публичного управления в регионах России на основе математических методов моделирования / Е. В. Логинова, Н. В. Лосева, А. А. Полковников, А. П. Калинин // Региональная экономика и управление : электрон. науч. журн. - 2017. - № 3 (51). Электрон. текстовые дан. - Режим доступа: http://eee-region.ru/article/5106/ (дата обращения: 10.06.2020). - Загл. с экрана.

Созыкин, А. В. Обзор методов обучения глубоких нейронных сетей / А. В. Созыкин // Вестник ЮУрГУ. Серия: Вычислительная математика и информатика. -2017. - Т. 6, № 3. - С. 28-59. 
Шолле, Ф. Глубокое обучение на Python / Ф. Шолле. - СПб. : Питер, 2018. - 400 с.

Homo institutius - Человек институциональный : [монография] / под ред. д-ра экон. наук О. В. Иншакова. - Волгоград : Изд-во ВолГУ, 2005. $854 \mathrm{c}$.

Loginova, E. Model of the assessment of the implementation of public administration in the regions of Russia / E. Loginova, N. Loseva, A. Polkovnikov // Proceedings of the International Scientific Conference "Competitive, Sustainable and Secure Development of the Regional Economy: Response to Global Challenges" (CSSDRE 2018). - 2018. - Vol. 39. P. 364-369. - Atlantis Press. Series: Advances in Economics, Business and Management Research (AEBMR). - Electronic text data. - Mode of access: https://www.atlantis-press.com/ proceedings/cssdre-18/25896381; https://doi.org/ 10.2991/cssdre-18.2018.76. - Title from screen.

Loginova, E. V. Realization of Population's Motivational Potential in the System of Public Administration as a Factor of Institutional Ensuring the Competitiveness of the Region / E. V. Loginova, N. V. Loseva, A. A. Polkovnikov // Competitive Russia: Foresight Model of Economic and Legal Development in the Digital Age. Proceedings of the International Scientific Conference in Memory of Oleg Inshakov (19522018). - Springer, 2020. - P. 276-284.

\section{REFERENCES}

Bessonova O.Je. Razdatochnaya ekonomika Rossii: evolyutsiya cherez transformatsii [Distribution Economy of Russia: Evolution Through Transformation]. Moscow, RPEN, 2006. 143 p.

Bessonova O.Je. Vektor institutsionalnogo razvitiya Rossii: ot kvazirynka k liberalnomu razdatku [The Vector of Russias Institutional Development: From Quasi-Market to Liberal Distribution]. Ekonomicheskaya sotsiologiya [Economic Sociology], 2008, vol. 9, no. 2, pp. 15-28.

Inshakov O.V. Teoriya faktorov proizvodstva $v$ kontekste ekonomiki razvitiya: nauch. dokl. na obshchem sobranii MAON (g. Moskva, 29 noyabrya 2002 g.) [The Theory of Production Factors in the Context of Development Economy. Scientific Report at the General Meeting of the International Academy of Education and Science (Moscow, November 29, 2002)]. Volgograd, Izd-vo VolGU, 2002. 92 p.

Inshakov O.V. «Yadro razvitiya» v kontekste novoy teorii faktorov proizvodstva ["Core of Development" in the Context of the New Theory of Production]. Ekonomicheskaya nauka sovremennoy Rossii [Economic Science of Modern Russia], 2003a, no. 1, pp. 11-25.

Inshakov O.V. Ekonomicheskie instituty i institutsii: $\mathrm{k}$ voprosu o tipologii i klassifikatsii [Social Nature and Specifics, Typology and Classification of Economic Institutions]. Sotsiologicheskie issledovaniya [Sociological Research], 2003b, no. 9, pp. 42-51.

Inshakov O.V. Instituty i institutsii v sovremennoy ekonomicheskoy teorii [Institutes and Institutions in Modern Economic Theory]. Vestnik Volgogradskogo gosudarstvennogo universiteta. Seriya 3, Ekonomika. Ekologiya [Journal of Volgograd State University. Economics], 2007, no. 11, pp. 6-21.

Inshakov O.V. Institutsiya i institut: problemy kategorialnoy differentsiatsii i integratsii [Institution and Institute: Problems of Categorical Differentiation and Integration]. Ekonomicheskaya nauka sovremennoy Rossii [Economic Science of Modern Russia], 2010, no. 3 (50), pp. 26-38.

Kirdina S.G. Ob institutsionalnykh matritsakh: tezisy teorii [Institutional Matrices: Theory Theses], 2005. URL: http://www.kirdina.ru/index.php? option $=$ com_content\&view $=$ article $\& i d=238$ (accessed 10 June 2020).

Kirdina S.G. Modeli ekonomiki v teorii institutsionalnykh matrits [Economic Models in the Theory of Institutional Matrices]. Ekonomicheskaya nauka sovremennoy Rossii [Economic Science of Modern Russia], 2007, no. 2 (37), pp. 34-51.

Kirdina S.G. Metodologicheskiy individualizm i metodologicheskiy institutsionalizm [Methodological Individualism and Methodological Institutionalism]. Voprosy ekonomiki [Economic Issues], 2013, no. 10, pp. 66-89.DOI: 10.32609/0042-8736-2013-10-66-89.

Kirdina-Chendler S.G. Zapadnye i ne-zapadnye institutsionalnye modeli vo vremeni $\mathrm{i}$ prostranstve [Western and Non-Western Institutional Models in Time and Space]. Voprosy teoreticheskoy ekonomiki [Questions of Theoretical Economics], 2018, no. 1, pp. 73-88. DOI: 10.24411/2587-7666-2018-00005.

Kleyner G.B. Sistemnaya paradigma V ekonomicheskikh issledovaniyakh: novyy podkhod [Systems Paradigm in Economic Research: A New Approach]. Tsivilizatsiya znaniy: rossiyskie realii: tr. Vosmoy nauch. konf., g. Moskva, 20-21 aprelya $2007 \mathrm{~g}$. [The Civilization of Knowledge: Russian Realities. Proceedings of the Eighth Scientific Conference, Moscow, April 20-21, 2007]. Moscow, RosNOU, 
2007, pp. 1-10. URL: https://kleiner.ru/wpcontent/uploads/2014/12/Sistemnayaparadigma-v-e \% 60 konomicheskih issledovaniyah.pdf.

Kleyner G.B. Intellektualnaya ekonomika tsifrovogo veka. Tsifrovoy vek: shagi evolyutsii [Intelligent Economy of the Digital Age. The Digital Age: Steps of Evolution]. Ekonomika i matematicheskie metody [Economics and Mathematical Methods], 2020, vol. 56, no. 1, pp. 18-33. DOI: 10.31857/ S042473880008562-7. URL: https://emm.jes.su/ S042473880008562-7-1 (accessed 19 June 2020).

Loginova E.V. Tsifrovye koordinaty sovremennogo rossiyskogo obshchestva: metodologiya issledovaniya [Digital Coordinates of Modern Russian Society: Research Methodology]. Vestnik Volgogradskogo gosudarstvennogo universiteta. Ekonomika [Journal of Volgograd State University. Economics], 2019, vol. 21, no. 3, pp. 15-28. DOI: https://doi.org/10.15688/ ek.jvolsu.2019.3.2.

Loginova E.V., Loseva N.V., Polkovnikov A. A., Kalinin A.P. Otsenka realizatsii publichnogo upravleniya $\mathrm{V}$ regionakh Rossii na osnove matematicheskikh metodov modelirovaniya [The Assessment Implementation of Public Administration in the Russians Regions on the Basis of the Mathematical Model Approach]. Regionalnaya ekonomika i upravlenie: elektron. nauch. zhurn. [Regional Economy and Management: Electronic Scientific Journal], 2017, no. 3 (51). URL: https://eee-region.ru/ article/5106/ (accessed 10 June 2020).

Sozykin A.V. Obzor metodov obucheniya glubokikh neyronnykh setey [Overview of Methods for
Training Deep Neural Networks]. Vestnik YuUrGU. Seriya: Vychislitelnaya matematika $i$ informatika [Bulletin of SUSU. Series: Computational Mathematics and Informatics], 2017, vol. 6, no. 3. pp. 28-59.

Cholet F. Glubokoe obuchenie na Python [Deep Learning in Python]. Saint Petersburg, Peter Publ., 2018. 400 p.

Inshakov O.V., ed. Homo institutius - Chelovek institutsionalnyy [Homo Institutius Institutional Man]. Volgograd, Izd-vo VolGU, $2005.854 \mathrm{p}$.

Loginova E., Loseva N., Polkovnikov A. Model of the Assessment of the Implementation of Public Administration in the Regions of Russia. Proceedings of the International Scientific Conference "Competitive, Sustainable and Secure Development of the Regional Economy: Response to Global Challenges" (CSSDRE 2018), vol. 39, pp. 364-369. (Atlantis Press. Series: Advances in Economics, Business and Management Research (AEBMR)). DOI: https:/ /www.atlantis-press.com/proceedings/cssdre18/25896381. https://doi.org/10.2991/cssdre18.2018.76.

Loginova E.V., Loseva N.V., Polkovnikov A.A. Realization of Population's Motivational Potential in the System of Public Administration as a Factor of Institutional Ensuring the Competitiveness of the Region. Competitive Russia: Foresight Model of Economic and Legal Development in the Digital Age. Proceedings of the International Scientific Conference in Memory of Oleg Inshakov (19522018). Springer, 2020, pp. 276-284.

\section{Information About the Authors}

Elena V. Loginova, Doctor of Sciences (Economics), Associate Professor, Deputy Director for Educational Work, Volzhsky branch of Volgograd State University, 40 Let Pobedy St., 11, 404133 Volzhsky, Russian Federation, elena.loginova@vgi.volsu.ru, https:/orcid.org/0000-0002-1579-411X

Natalia V. Loseva, Candidate of Sciences (Physics and Mathematics), Associate Professor, Lecturer, Volzhsky branch of Volgograd State University, 40 Let Pobedy St., 11, 404133 Volzhsky, Russian Federation, loseva_nat@vgi.volsu.ru, https://orcid.org/0000-0002-1939-8499

Aleksandr A. Polkovnikov, Candidate of Sciences (Physics and Mathematics), Associate Professor, Head of the Department of Mathematics, Computer Science and Natural Sciences, Volzhsky branch of Volgograd State University, 40 Let Pobedy St., 11, 404133 Volzhsky, Russian Federation, polkovnikov@vgi.volsu.ru, https://orcid.org/0000-0002-0869-3687

\section{Информация об авторах}

Елена Викторовна Логинова, доктор экономических наук, доцент, заместитель директора по учебно-воспитательной работе, Волжский филиал Волгоградского государственного универси- 
тета, ул. 40 лет Победы, 11, 404133 г. Волжский, Российская Федерация, elena.loginova@vgi.volsu.ru, https://orcid.org/0000-0002-1579-411X

Наталия Владимировна Лосева, кандидат физико-математических наук, доцент, преподаватель, Волжский филиал Волгоградского государственного университета, ул. 40 лет Победы, 11, 404133 г. Волжский, Российская Федерация, loseva_nat@vgi.volsu.ru, https://orcid.org/0000-0002-1939-8499

Александр Александрович Полковников, кандидат физико-математических наук, доцент, заведующий кафедрой математики, информатики и естественных наук, Волжский филиал Волгоградского государственного университета, ул. 40 лет Победы, 11, 404133 г. Волжский, Российская Федерация, polkovnikov@vgi.volsu.ru, https://orcid.org/0000-0002-0869-3687 